\title{
TYPOLOGICAL CHARACTERIZATION OF ANCIENT TOWN WALLS FOR DISASTER PREVENTION AND MITIGATION: THE MO.M.U. PROJECT
}

\section{ANNA DE FALCO ${ }^{1}$, FRANCESCA GIULIANI ${ }^{1 *}$, DANIELA LADIANA ${ }^{2}$, LEDIANA RJOLLI $^{1}$, DAVIDE BORDO ${ }^{1}$, FRANCESCA GAGLIO ${ }^{1}$ AND MICHELE DI SIVO ${ }^{1}$}

\author{
${ }^{1}$ Department of Engineering of Energy, Systems, Territory and Construction, \\ University of Pisa, Largo Lucio Lazzarino, Pisa 56122, Italy, www.destec.unipi.it/ \\ ${ }^{2}$ Department of Architecture, University of Chieti-Pescara, Viale Pindaro 42, 65127 Pescara, Italy, \\ www.dda.unich.it/ \\ *Corresponding author e-mail: francesca.giuliani@ing.unipi.it
}

Keywords: Town Walls, Masonry Structures, Risk Prioritisation, Heritage Conservation.

\begin{abstract}
The problem raised by the steadily increasing number of failures in ancient town walls has recently attracted much interest. This typology of cultural heritage has always played a critical role in shaping local identities and still holds great potential as a cultural resource but poses substantial challenges in management terms. In fact, multi-disciplinary methodologies for their study and analysis are missing. The MO.M.U. project aims to safeguard ancient town walls in Tuscany (Italy) by introducing an integrated framework for their knowledge, diagnostic, assessment, monitoring and management. The proposed approach employs innovative non-invasive technologies and introduces a multi-hazard risk prioritisation methodology to address preventive conservation and programme interventions.
\end{abstract}

\section{INTRODUCTION}

Nowadays there is a growing awareness of the vulnerabilities and exposure of Italian cultural heritage to natural hazards and human-induced threats. Approaches to risk analysis and reduction of immovable cultural heritage are usually based on typological considerations, thus identifying several architectural classes (e.g. ordinary buildings, churches, towers, palaces) accounting for their different response to any hazardous event. A peculiar class of historical constructions involves masonry town walls built as a defence system of the inner historic centre.

Ancient town walls play a critical role in shaping local identities and still hold great potential as cultural resources but pose substantial challenges in management terms. Although national regulations have been issued to improve the structural safety of heritage-listed monuments and buildings [1], a systematic strategy for Disaster Risk Reduction (DRR) of town walls is missing and actions for their preservation are still occasional. Recent damage suffered by historical town walls in the Region of Tuscany, specifically in the historic settlements of Volterra (2014), Magliano in Toscana (2012 - 2014), Pistoia (2011 - 2020), 
Cana di Roccalbegna (2013 - 2020), Poggio a Caiano (2017) and San Gimignano (2018), have raised attention on the growing vulnerability of heritage of urban fortifications.

Preventive and planned conservation entails the protection of architectural heritage and is founded on the attentive identification of situations of risk and the systematic planning of minimally invasive interventions [2]. The knowledge of materials, technologies, stratifications and contexts is paramount and is able to favour a systemic approach. These aspects affect the correctness of risk analysis that requires a critical judgment founded on a reading and interpretation of the object to be preserved and the phenomena to which it is subjected. In the architectural heritage domain, simplified multi-hazard approaches represent a significant step forward in the prioritisation of risk reduction measures [3] [4] [5]. Moreover, qualitative index-based methodologies can identify situations when detailed assessments are needed [6].

Starting from 2019, the Regional Government of Tuscany is promoting a systemic research regarding walled historic centres with the objective to develop a fit-for-purpose methodology to inform risk governance in its territory. The MO.M.U. (MOnitoraggio delle Mura Urbane monitoring of town walls) project brings an innovative contribution towards the analysis of ancient town walls in Italy, focusing on defining methods, technologies and tools for their multi-hazard risk analysis and monitoring. The project herein presented adopts a systemic approach to the organization of processes, ranging from the territorial scale to the more minute scale of individual elements, thus allowing for the multi-level risk prioritisation,

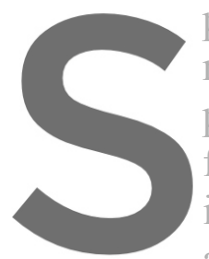
preventive conservation recently occurred in parameters affecting framework and the investigations. The rese allows for storing and cla
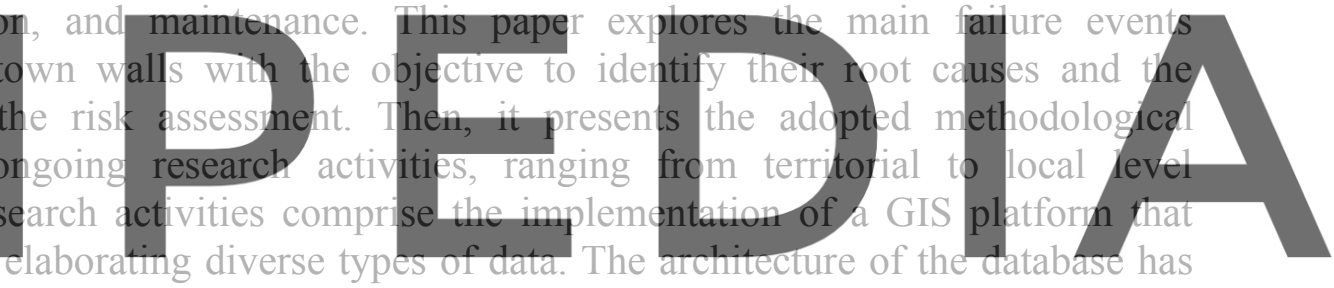
been defined according to the research scope and supports knowledge management for risk

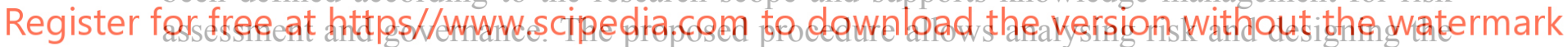
layout of a monitoring system, thus allowing for the multi-level risk prioritisation, preventive conservation, and management of maintenance.

\section{MOTIVATION AND AIMS OF THE PROJECT}

\subsection{Failure of town walls in Tuscany}

Since 2011, numerous events regarded the collapse of town walls in Tuscany. The main events occurred in Pistoia (PT), Magliano in Toscana (GR), Cana di Roccalbegna (GR), Volterra (PI), Poggio a Caiano (PO) and San Gimignano (SI). In some cases, the collapse recurred after a few years.

Pistoia is an important city that still shows traces of its Gallic, Ligurian, Etruscan and Roman past. On September 19, 2011, a portion of about 25 meters of medieval town walls outwardly collapsed. The curtain wall facing the city centre remained standing and the outer layer crumbled (Fig. 1). The consequence did not result in deaths or injuries, but debris fell on some greenhouses, causing economic losses to agricultural activities. The collapse was triggered by heavy rain in an already critical situation. The main factors influencing the 
collapse were the wall slenderness, its height, the difference between the floor levels on the two sides of the wall and the poor quality of the masonry. Walls are made of river pebbles and are weakened by texture irregularity, traces of poorly chosen interventions and lack of maintenance [7]. In September 2020, the same curtain completely collapsed for a length of 30 $\mathrm{m}$. In this case, no extreme climatic events preceded the disaster.
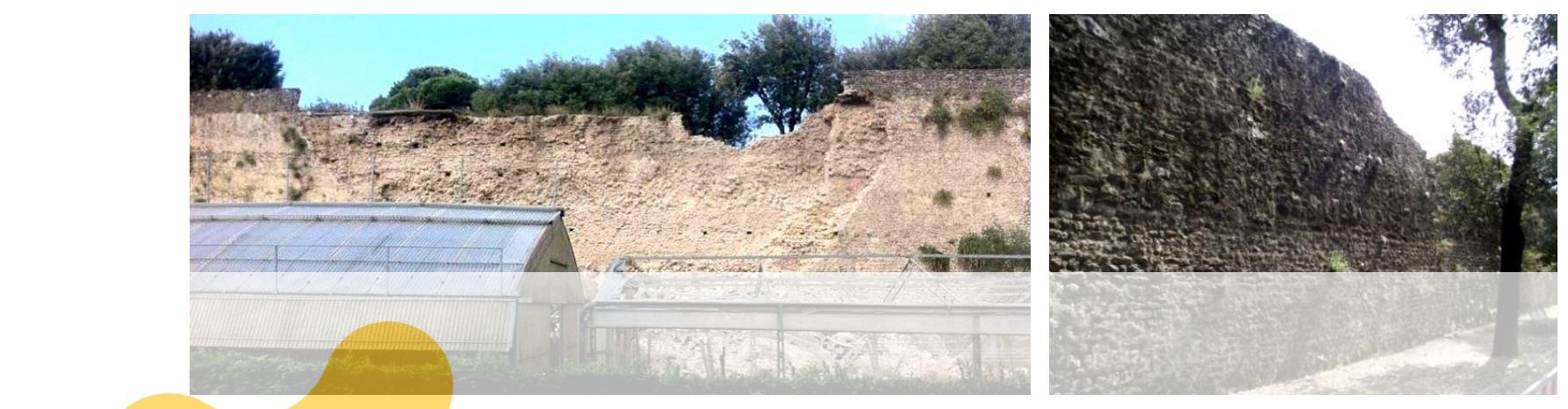

Figure 1: Collapse of the city walls of Pistoia (September 19, 2011). On the left: the failure seen from the outer side; on the right: the failure seen from the city centre.

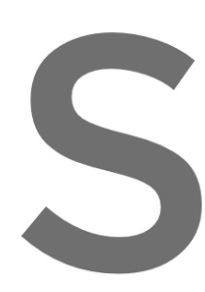

On November 13, 2012, the south-western tower of the medieval town walls of Magliano in Toscana collapsed. After the middle of the XVII century, they were no longer used for
military purposes and their maintenance was neglected. This situation has favoured the
construction of new masonry buildings adjacent to the curtain that was thus used as a load
bearing wall. The so-called Torrione, about $20 \mathrm{~m}$ high and $9 \mathrm{~m}$ wide, was made of a stone
masonry curtain covering a rocky outcrop in the lower part and containing the earth/in the upper part. The structure suddenly collapsed following an extreme meteorological event. The

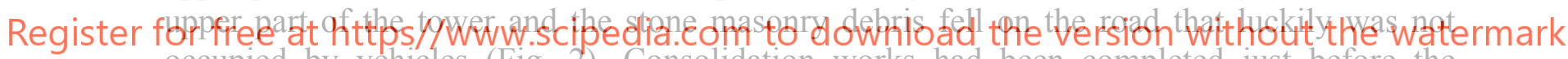
occupied by vehicles (Fig. 2). Consolidation works had been completed just before the disaster: the large and numerous full-height cracks had been closed and the joints repointed. The closure of these natural drainage holes probably caused the collapse during an exceptional rainfall, when the weep holes at the base were obstructed by a great amount of soil accumulated in the inner part of the tower.

After just two years, on December 15, 2014, a second collapse affected a portion of the curtain in the south-western area, following a further rainy event of considerable intensity and duration. The structure was a retaining stone masonry wall of about $8 \mathrm{~m}$ height and $17 \mathrm{~m}$ length. The collapse was caused by the water pressure on the back of the wall, due to the poor drainage system. The event was preceded by cracks and deformations that appeared on the wall since the previous July. Nevertheless, it was not possible to avoid the collapse which, however, took place without consequences, thanks to the preventive countermeasure provided in proximity of the road.

On October 5, 2013 about 13 meters of town walls collapsed during a heavy rainfall in an ancient small town, Cana di Roccalbegna (Fig. 3). The system was made of a stone masonry retaining wall dating back to the XV century, surmounted by a reinforced concrete slab which formed the base of a panoramic viewpoint square. The masonry was inhomogeneous in terms 
of material and construction techniques. The failure was caused by the erosion due to incorrect water drainage and increase of hydrostatic pressure behind the wall during the heavy rainfall event. The rubble reached a building, which fortunately was only hit by minute debris, and the street below, where a parked car was buried. On 21 August 2020 the reinforced concrete slab suddenly broke during the execution of the consolidation works. Four houses have been evacuated and a part of the village has become inaccessible due to debris.

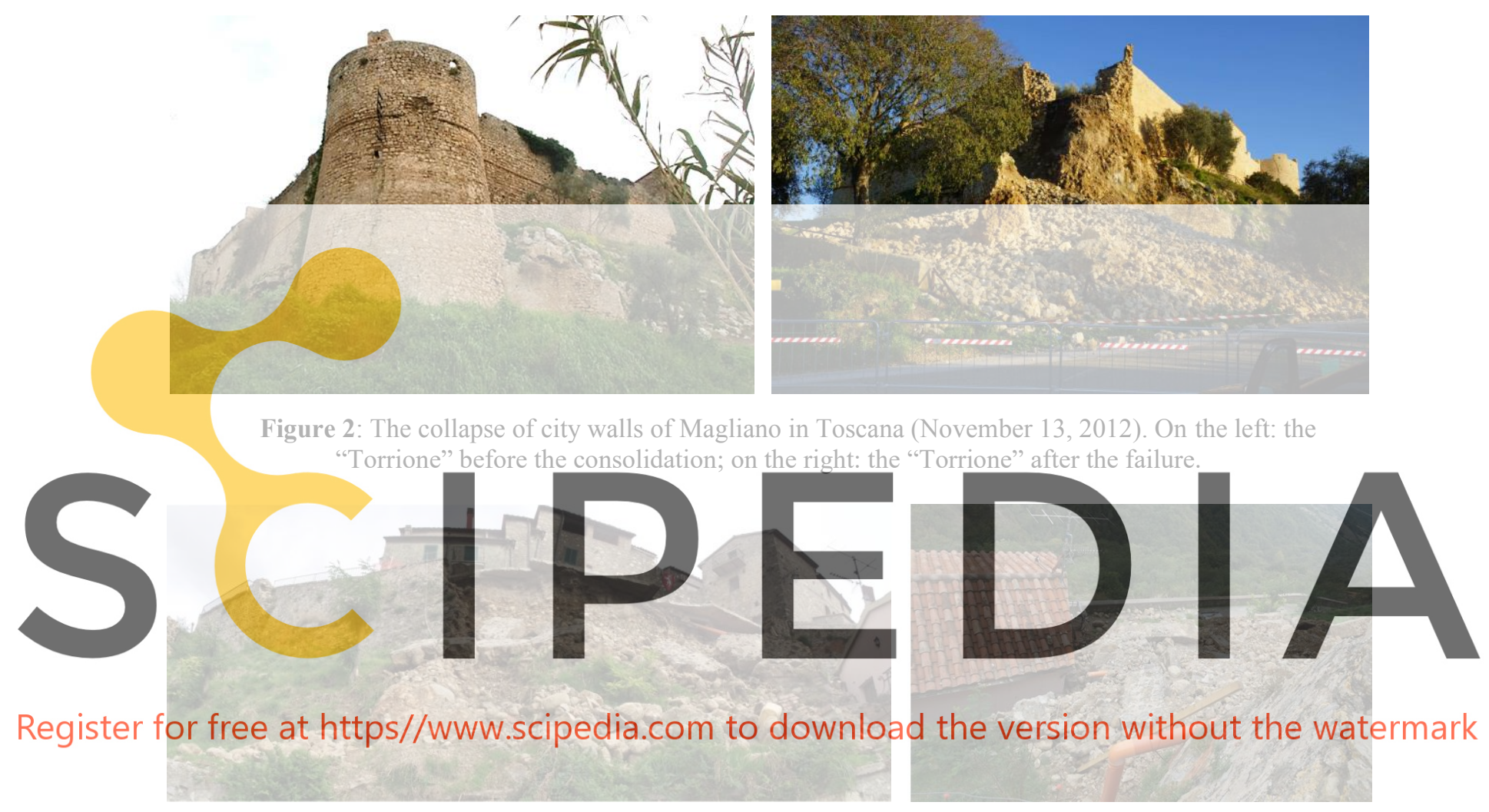

Figure 3: Collapse of the city walls in Cana di Roccalbegna (October 5, 2013). On the left: the collapse seen from below; on the right: the debris near the building below the wall.

On January 31, 2014 about 35 meters of the town walls in the south-western side of Volterra suddenly collapsed, after a series of heavy rainfall events. Volterra is a walled hilltop town in Tuscany, one of the most important Etruscan settlements, successively developed as a medieval centre. The failure involved a $9.5 \mathrm{~m}$ high segment of a stone masonry retaining wall that embraces the city centre, laying bare the foundations of the historical masonry buildings above (Fig. 4). Luckily, there were no casualties, but the buildings located at a distance of a few meters from the wall were slightly damaged. The main causes of the collapse are the incoherent sandy terrain behind the curtain wall weakened by previous repeated water infiltrations due to the old sewer system of the historic centre, and the water from the heavy rains of January, which increased the hydrostatic pressure on the curtain [8]. Added to this is the intrinsic weakness of the masonry of the collapsed portion, due to the significant and repeated restorations during time, from the middle age up to now. On March 3, 2014 another 
failure affected the unstable wall corner located about two hundred meters from the abovementioned portion toward the South. The collapse was preceded by some cracks on the irregular and inhomogeneous masonry wall. In that circumstance, a part of the embankment slid downwards, despite the remedial works with steel anchors.
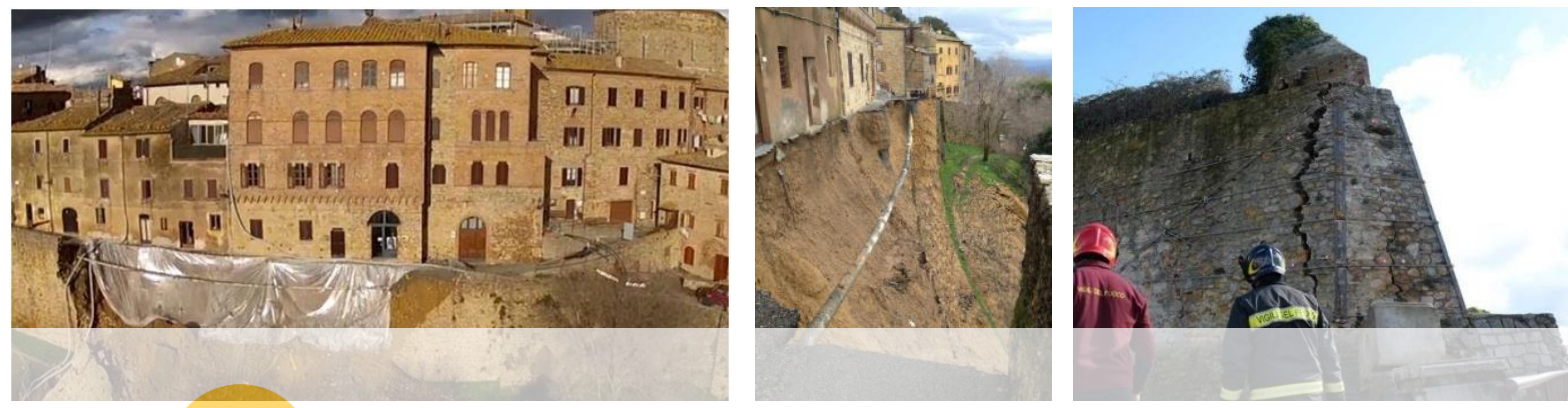

Figure 4: The collapse of the city walls of Volterra (January 31, 2014).

As emerges from these emblematic cases, climate change and natural events are seriously affecting historical town walls, but even local technological ruptures can potentially cause the collapse of great sections. Two different hazard conditions can be thus identified: the first is associated to ordinaly ground subsidence, and time; and the second floods, earthquakes, lifei

2.2 The MO.M.U. project: aims and activities
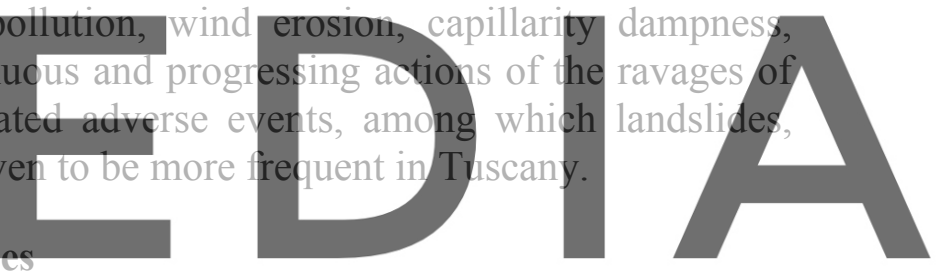

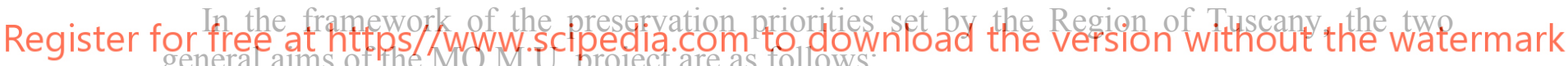
(t)

- to strengthen the role of Local Governments in the preventive and planned conservation of ancient town walls and to raise awareness of the importance of disaster risk governance in the architectural heritage domain.

- to establish a regional multi-hazard risk prioritisation framework for the safeguard of town walls, applying knowledge from multiple disciplines.

Based on these general objectives, seven specific aims are established:

- to create a digital archive that documents the town walls' history, building technologies, construction phases, alterations and modifications, structural materials, past restoration and maintenance works.

- to define fit-for-purpose forms for data collection and organisation and to identify the most effective tools and technologies for the documentation of town walls.

- to identify typical deterioration and damage patterns of historical town walls, and to create a portfolio that accounts for the different materials (mainly stone and brick), architectural typologies (retaining, isolated and massive walls), territorial topography (coast, valley, plain, mountain), century-old transformations. The step requires a preliminary definition of a diagnosis methodology. 
- to develop, calibrate and test a multi-level large-scale methodological model to assess the risks of ancient town walls based on specifically formulated performance demands.

- to create a GIS-based system for managing and elaborating georeferenced data and documents from diverse sources, as well as conducting risk assessments of town walls.

- to conduct benchmarking activities on a set of case studies by means of site inspections, surveys, documentation, risk assessment activities in order to test the overall framework.

- to define monitoring actions and intervention measures for planned and preventive conservation, using conventional and innovative technologies, such as Geographical Information Systems (GIS), GPS-based photogrammetry, interferometric Synthetic Aperture Radar (SAR) techniques.

\section{METHODOLOGY}

The procedure developed within the MO.M.U. project consists in a simplified approach to multi-hazard risk analysis and governance that can be used by officials and administrators in Local or Regional Governments who are not experts in the field(s).

Town walls are deeply integrated into the urban fabric and their accessibility can be difficult since many constructions, even private housing units, have been progressively reusing their structural elements. Besides, the application of invasive tests is not feasible due to the heritage value and the impossibility to alter the physical aspect. Therefore, digital noninvasive technologies have been included into the procedure due to their ability to support the
data acquisition, collection, management and elaboration. The combination of traditional
geometric surveys and more innovative techniques, e.g GPS-enabled digital cameras, allows
for a complete and extensive photogrammetric documentation of the town walls. Additionally,
mobile applications factitate the recording and collection of data during field surveys [9]. Emphasis is given to the development of a GIS platform that was specifically designed to

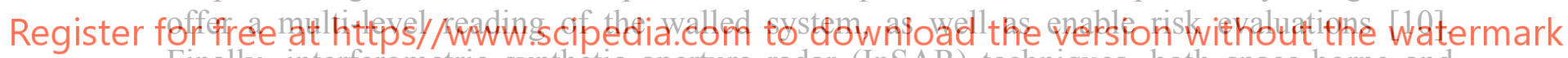
Finally, interferometric synthetic aperture radar (InSAR) techniques, both space-borne and terrestrial, have shown their effectiveness in providing measurements of ground displacements [8].

The proposed multi-level methodology consists of four phases (Fig. 5) characterised by an increasing level of knowledge, detail and investigation effort. Each level is connected to the previous one and only the progression to the last level allows for establishing monitoring and intervention activities.

The 'Level 0 - Inventory and geolocalisation' phase aims to collect data on the town walls located into the Tuscany Regional territory and thus to gain large-scale knowledge on the overall number and main features for their management. Each walled system is analysed as a whole and documented accounting for previous studies, historical information and archival material. A specific GIS-based form, the 'level 0 census form', is developed for the purpose. It describes several relevant aspects of the walls, such as the orography, hydrography and topography of the territory, the construction typology, morphology, technologies and materials, the construction and transformation phases, and also the previous restoration and maintenance works. The form is organized in nine sections: (1) localisation and geomorphological data of the site; (2) general information and legal status of protection; (3) 
general description and photographic archive; (4) current state; (5) accessibility and usability; (6) history and historical documents; (7) documentation of past interventions; (8) description of the context; (9) decomposition into homogeneous subsystems.

LEVEL 0

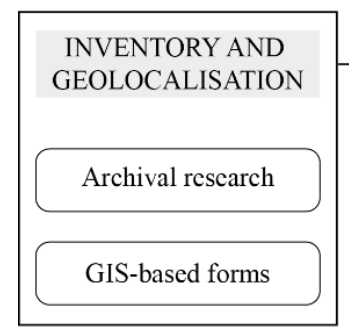

LEVEL
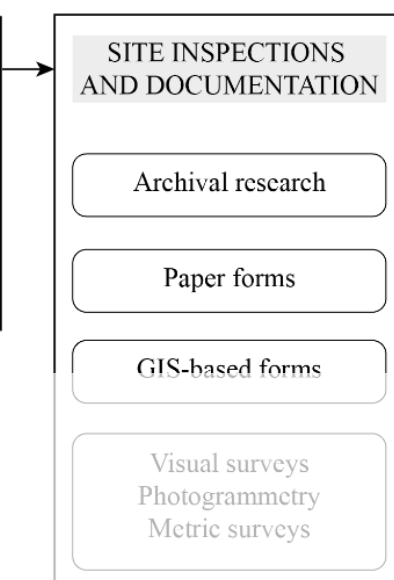

LEVEL 2

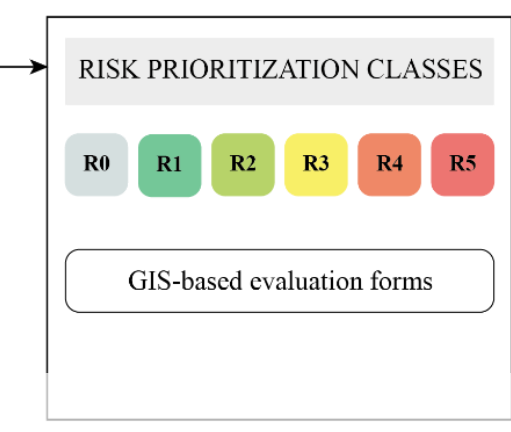

LEVEL 3

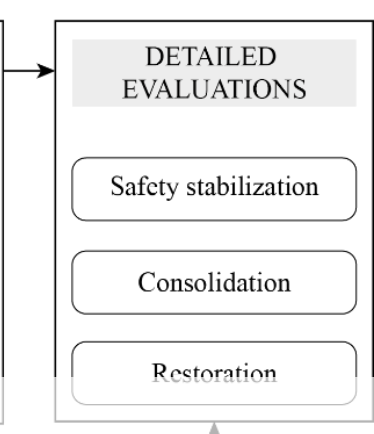

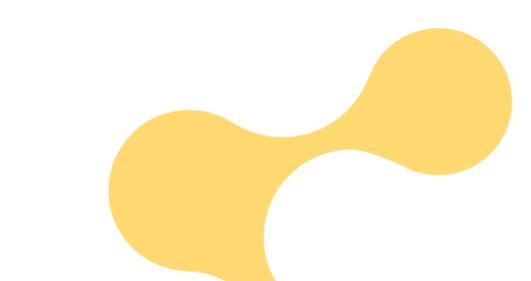

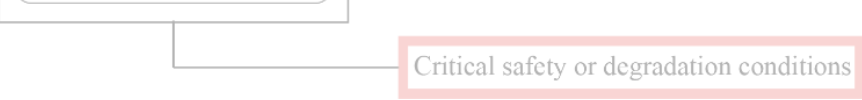

\section{Critical safety or degradation condition}

Figure 5: Multi-level methodology for the risk prioritisation and management

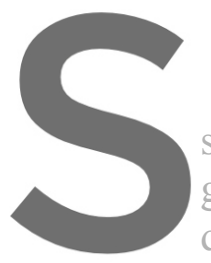

The 'Level 1 - Site
systems correspondi
cuments and conduct
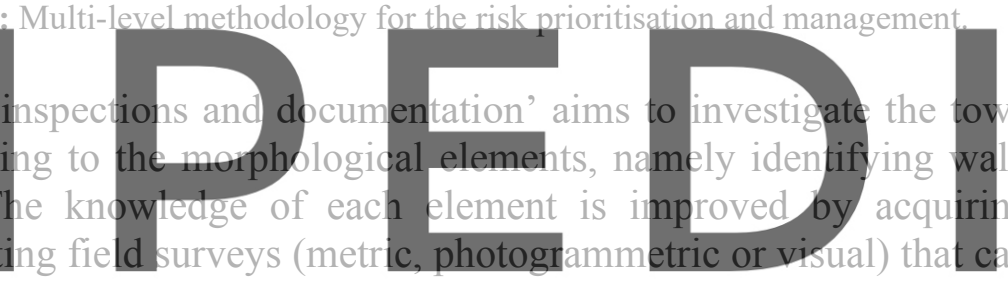

correct and integrate the data collected for Level 0. Finally, this step allows for identifying

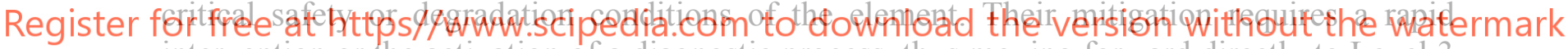
intervention or the activation of a diagnostic process, thus moving forward directly to Level 3 (Fig. 5). A 'level 1 documentation form' is developed entailing a detailed analysis of the elements, both on-site and off-site. To this end, the form can be filled in either on paper or on the GIS platform, perhaps using mobile GIS applications. The form comprises seven sections: (1) localisation; (2) historical, morphological, typological, geometrical and current state characterisation; (3) accessibility and usability; (4) material archive (masonry materials, stratigraphy units); (5) documentation of past interventions; (6) description of the context and hazardous conditions; (7) critical conditions to activate the diagnostic process and the intervention.

The 'Level 2 - Risk prioritisation classes' aims to evaluate risks on town walls by means of a simplified procedure that depends on six performance demands. The performances have been identified taking into account the heritage significance and past failures of Tuscan town walls. Risk is assessed as a function of hazards, vulnerability, and exposure [11], whose characterisation varies according to the performance demand, as specified in Tab. 1. Hazards account for progressive and catastrophic actions and can be identified according to hazard maps and data on past events in the area. Vulnerabilities are associated to ordinary or extraordinary conditions. The first ones are assessed by means of a fit-for-purpose form 
regarding the surveyed degradation and damage processes that are scored with two parameters, magnitude and extension. Instead, extraordinary conditions are evaluated by means of hazard-specific forms that entail a preliminary identification of the elements exposed to each hazard. Finally, exposure refers to the walled system itself as cultural heritage, as well as people, objects, buildings, roads or any element that can be potentially damaged by the failure of the town walls. Six risk classes have been considered, ranging from $\mathrm{R} 0$ to R5 [5]: R0 is assigned to units that are not exposed to any hazard; R1 and R2 are associated with acceptable levels of risk requiring on-site inspections; R3 is at the limit of acceptability and therefore requires regular monitoring actions; R4 and R5 are associated to unacceptable and critically unacceptable levels, respectively. Each element is subdivided into a number of units on which the evaluation is performed by means of several GIS-based forms.

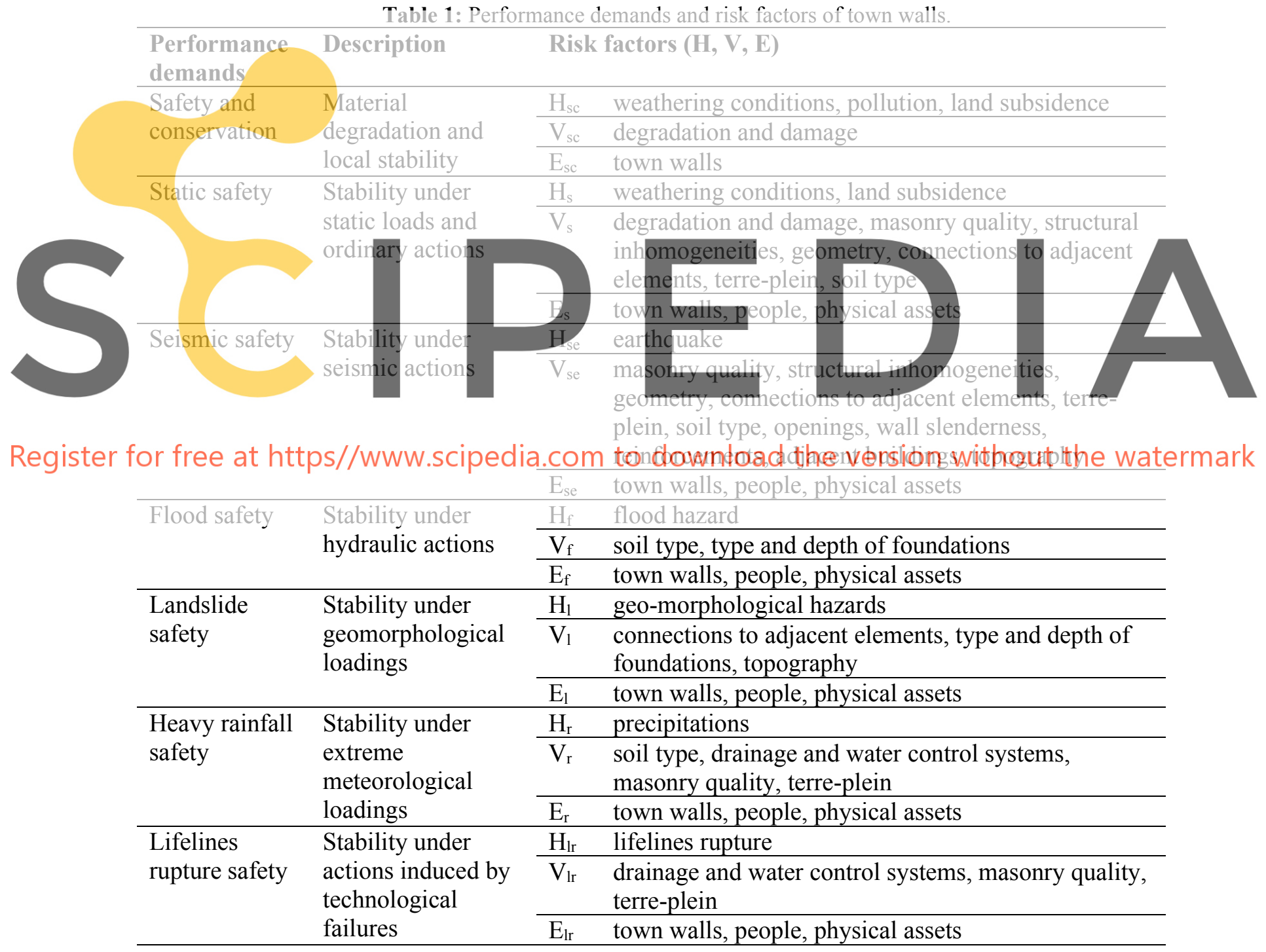


At first, the evaluator is asked to fill in the 'level 2 degradation and damage patterns form', which is based on the portfolio of typical damage and degradation patterns of Tuscan town walls. For each unit of the walled system, this form allows for defining a vulnerability index as the normalised weighted sum of the products between magnitude and extension scores. Then, specific vulnerability forms $\left(\mathrm{V}_{\mathrm{sc}}, \mathrm{V}_{\mathrm{s}}, \mathrm{V}_{\mathrm{se}}, \mathrm{V}_{\mathrm{f}}, \mathrm{V}_{\mathrm{l}}, \mathrm{V}_{\mathrm{r}}, \mathrm{V}_{\mathrm{lr}}\right)$ are introduced to account for the liability of walls to be damaged under different actions $\left(\mathrm{H}_{\mathrm{sc}}, \mathrm{H}_{\mathrm{s}}, \mathrm{H}_{\mathrm{se}}, \mathrm{H}_{\mathrm{f}}, \mathrm{H}_{\mathrm{l}}, \mathrm{H}_{\mathrm{r}}, \mathrm{H}_{\mathrm{rr}}\right)$, as defined by the performance demands (Tab. 1). The overall degradation and damage state is the basis for the vulnerability evaluation in every performance. Exposure is distinguished between the safety and conservation case $\left(\mathrm{E}_{\mathrm{sc}}\right)$ regarding only the town walls and the other cases $\left(E_{s}, E_{s e}, E_{f}, E_{1}, E_{r}, E_{l r}\right)$ regarding town walls, people, and physical assets.

The 'Level 3 - detailed evaluations' involves detailed investigations and monitoring activities on town walls subjected to risk levels R3, R4, and R5. The step is mandatory to conduct safety stabilisation, restoration or consolidation works.

\section{RESEARCH ACTIVITIES}

\subsection{Territorial census of Tuscan town walls (Level 0 )}

The territorial-level census regards 140 ancient town walls (Fig. 6) in Tuscany that are under investigation with the cooperation of regional and local authorities who are in charge of

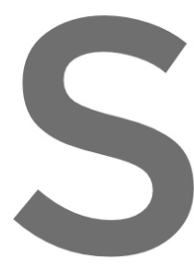
their preservation. T requested by the Levdl 0 census images and recent photograph Register for free at https//www.scipedia.
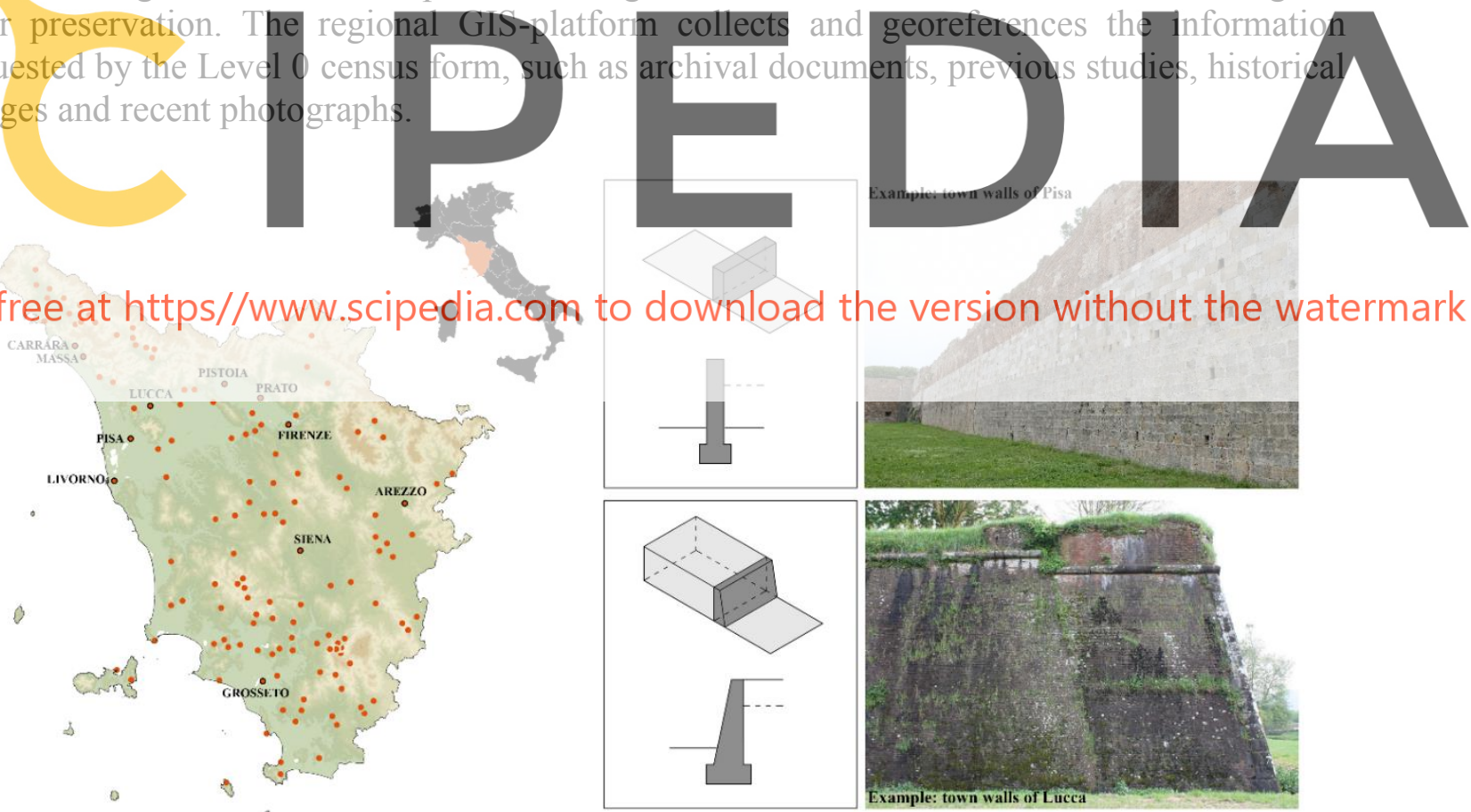

Figure 6: Multi-level methodology for the risk prioritisation and management.

The comparative analysis highlights a quite complex and varied picture, with similarities in the building techniques within geographical areas that were fortified in the same period by common governments, often over pre-existing defence systems. The configuration of the 
walls is strongly affected by the territorial topography, particularly in mountain areas where fortifications were built as retaining walls over slopes and cliffs. Conversely, town walls located on valleys and plains present more regular shapes. Most walled systems date back to Medieval times, in some cases incorporating the more ancient defensive systems, particularly Etruscan in the Southern part of Tuscany.

A lower number of cases present Modern fortifications built approximately from the second half of the XV century. Medieval walled systems are usually composed of isolated, slender walls connecting high-rise towers, whereas Modern ones present thicker scarp-shaped sections and bastions, with terre-pleins behind the walls. Town walls are made of stone masonry (mainly Medieval walls) and brick masonry (mainly Modern walls) whose composition, geometry and arrangement depend on local materials and workmanship. Materials are often varied, and several building techniques can be found along the walled system, with many local alterations that can be difficult to identify. The current state is the product of century-old transformations that affect the structural homogeneity and the flow of internal forces within the structure. The wall texture bears signs of these changes, as well as past collapses and alterations, and may reveal the quality of the masonry and its attitude to crumble, especially under seismic actions.

4.2 Local investigations (Level 1 and Level 2): the town walls of Pisa
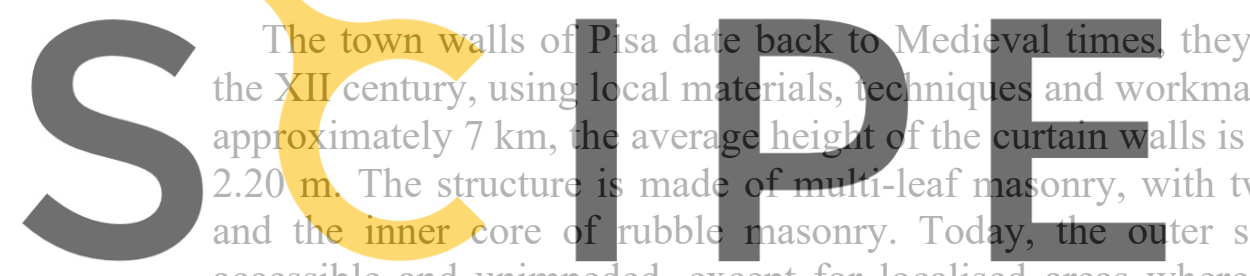

accessible and unimpede
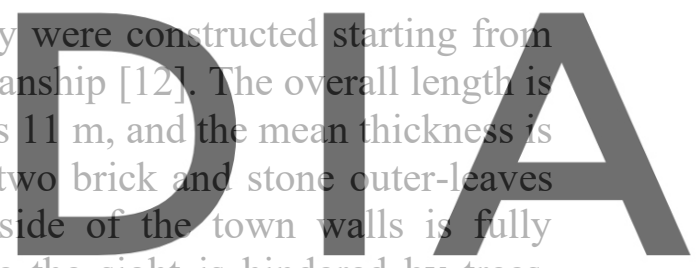

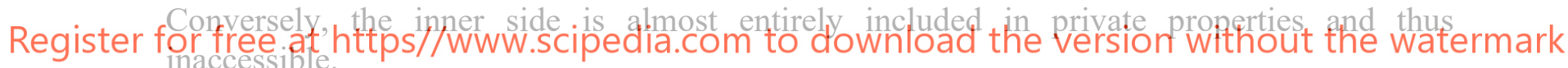

The walled system comprises different morphological elements, such as curtains (codified as CUR), towers (TOR), gates (GATE), and bastions (BAS). Each element has been deeply investigated thanks to the Level 0 and Level 1 forms. Due to the massive dimensions of town walls, a rapid photogrammetric surveying workflow has been adopted in order to obtain results of the entire investigated portion in a reasonable time. Photographs were acquired using an iPhone 11 camera having a resolution of $12 \mathrm{MP}$ and a 1/2.55-inch sensor, with GPS on. The acquisition was done over several days at different times, to have uniform illumination, avoiding strong direct lights and hard shadows. Ortho-images have been processed from 3D photogrammetry models.

The state of conservation and the structural conditions of the town walls of Pisa are quite varied and tend to be better in touristic areas with public accessibility. Some areas present critical conditions that may affect the structural performance, such as vertical cracks, out of plumbs, and corner failure mechanisms mainly caused by ground subsidence. The presence of differential land subsidence in critical areas is confirmed by InSAR vertical displacement measures that provide punctual time series of the last 5 years. Common degradation patterns concern higher plants, vegetation, superficial loss of materials, moisture and efflorescence. 
Partial results are illustrated in Fig. 7, which shows the ortho-image of the portion including GATE.13 and CUR.27. The element is divided into units (labelled from 21 to 30) having a length of $2 \mathrm{~m}$ that have been evaluated by means of the Level 2 forms. Coloured stripes identify different risk levels: green squares are characterised by lower risk levels, while red ones present higher risk levels. Two sample performance levels are considered, namely 'safety and conservation' and 'static safety'. The first one involves the preliminary evaluation of degradation and damage patterns, highlighting the worst conditions determined by the presence of moisture, vegetation (both on the wall surface and the top), cracks among joints, and block's erosion. The second performance level entails the assessment of exposure in the facing area having a minimum width equal to the height of the wall. Significant parameters are human flows, material assets, road type, parked vehicles.
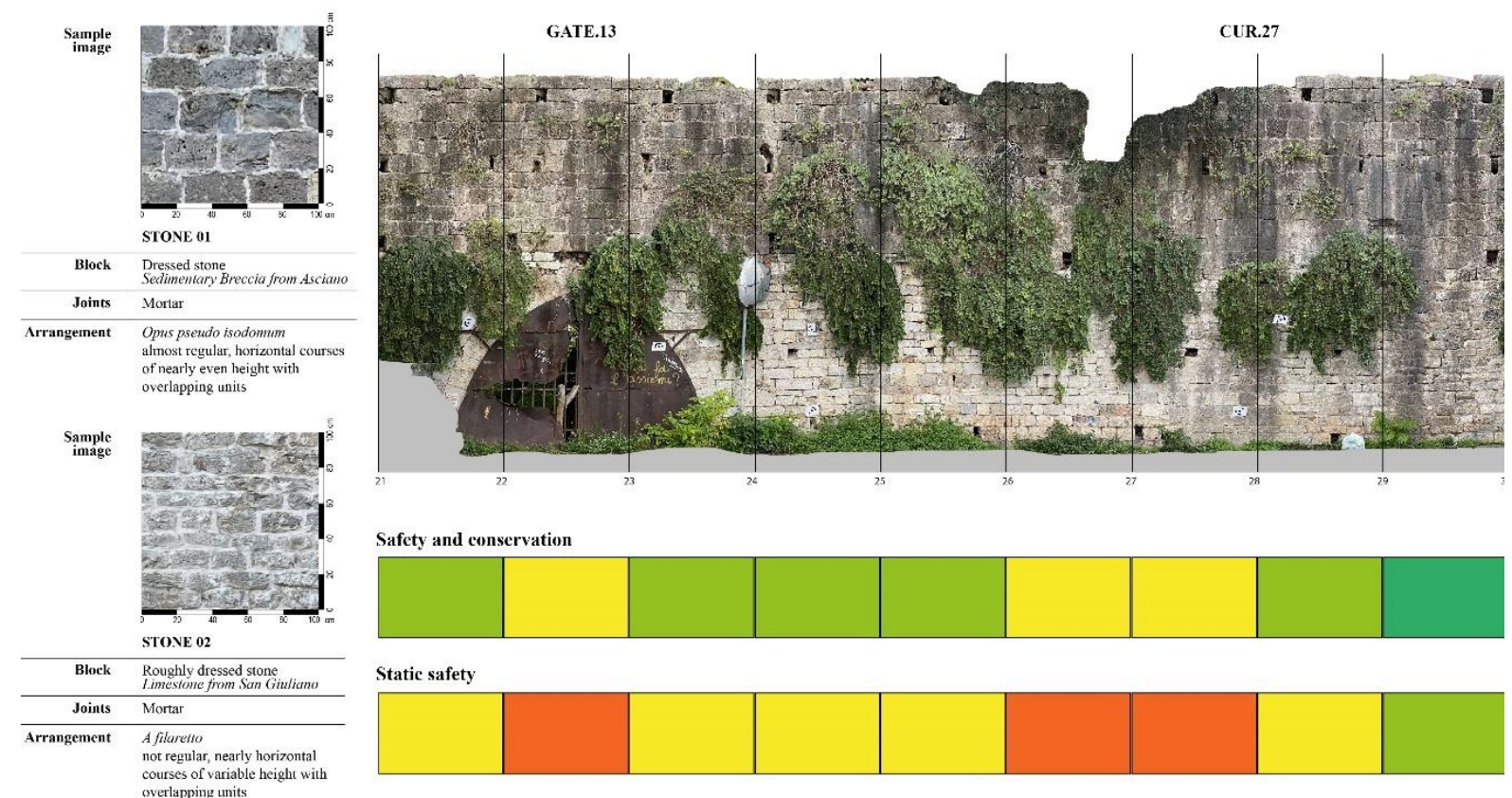

Figure 7: The town walls of Pisa. Masonry typologies and evaluation of risks (Level 2) in two sample performance levels. The coloured stripes recall the six risk levels presented in Fig. 5.

\section{CONCLUSIONS}

This paper introduced the MO.M.U. project and presented a general overview on the methodology developed for the research scope. Structural safety and risk analysis are rooted in the acquisition of knowledge about the construction under investigation, specifically the geometry, building techniques, materials, damage state, century-old evolutions, material stratifications and territorial context. Starting from the presentation of the main failure events recently occurred in Tuscan town walls, we presented the root causes and parameters affecting the risk assessment. Then, a multi-level methodology has been proposed and applied to the Regional basin. Territorial investigations allowed for characterising the main typological features in the area. Besides, the multi-hazard risk prioritisation procedure is a 
first attempt to introduce a simplified quantification of physical vulnerability and exposure. Benchmarking studies concerned the application of the index-based risk prioritisation procedure on the town walls of Pisa. Once calibrated and validated, this approach to risk analysis and governance will be used by governmental officials and administrators. The procedure has potential to be applied to different typologies of historic walls located in diverse geographical areas. In this way, they can achieve planned and preventive conservation that entails a periodic knowledge updating to determine the evolution of risk factors.

Acknowledgements. The authors wish to acknowledge the Tuscany Region and the Consorzio LaMMA (Laboratorio Monitoraggio e Modellistica Ambientale) for the support.

\section{REFERENCES}

[1] Presidenza del Consiglio dei Ministri. Direttiva del Presidente del Consiglio dei Ministri per valutazione e riduzione del rischio sismico del patrimonio culturale con riferimento alle norme tecniche per le costruzioni. G.U. n. 47 (2011).

[2] Della Torre, S. Italian perspective on the planned preventive conservation of architectural heritage. Frontiers of Architectural Research (2020).

[3] Giuliani, F., De Falco, A., Cutini, V., and Di Sivo, M. A simplified methodology for risk analysis of historic centers: the World Heritage Site of San Gimignano, Italy. International Journal of Disaster Resilience in the Built Environment (2020).

[4] Sevieri, G., Galasso, C., D’Ayala, D., De Jesus, R., Oreta, A., Grio, M. E. D. A., and Ibabao, R. A multi-hazard risk prioritisation framework for cultural heritage assets. Natural Hazards and Earth System Sciences (2020) 20(5): 1391-1391.

[5] Moratti, M., Gaia, F., Martini, S. et al. A methodology for the seismic multilevel assessment of unreinforced masonry church inventories in the Groningen area. Bull Earthquake Eng (2019) 17: 4625-4650.

[6] Romão, X., Paupério, E., and Pereira, N. A framework for the simplified risk analysis of cultural heritage assets. Journal of Cultural Heritage 20 (2016): 696-708.

[7] Andreini, M., De Falco, A., Giresini, L., and Sassu, M. Collapse of the historic city walls of Pistoia (Italy): causes and possible interventions. In: Advances in Civil Structures. Applied Mechanics and Materials (2013) 352: 1389-1392, Trans Tech Publication.

[8] Pratesi, F., Nolesini, T., Bianchini, S., Leva D., Lombardi L., Fanti R., and Casagli N. Early Warning GBInSAR-Based Method for Monitoring Volterra (Tuscany, Italy) City Walls. IEEE Journal of Selected Topics in Applied Earth Observations and Remote Sensing (2015) 8(4): 17531762.

[9] Nowak, M. M., Dziób, K., Ludwisiak, Ł., and Chmiel, J. Mobile GIS applications for environmental field surveys: A state of the art, Global Ecology and Conservation (2020) 23: e01089.

[10] Moreno, M., P. Ortiz, and R. Ortiz. "Vulnerability Study of Earth Walls in Urban Fortifications Using Cause-Effect Matrixes and GIS: the Case of Seville, Carmona and Estepa Defensive Fences." Mediterranean Archaeology and Archaeometry (2019) 19(3): 119-138.

[11] Birkmann, J., Cardona, O.D., Carreño, M.L. et al. "Framing vulnerability, risk and societal responses: the MOVE framework." Nat Hazards 67 (2013), 193-211. DOI: 10.1007/s11069-0130558-5

[12] Bevilacqua, M.G., Caciagli, C. and Salotti, C. Le mura di Pisa: fortificazioni, ammodernamenti e modificazioni dal XII al XIX secolo. Edizioni ETS (2011). 